\title{
El edificio de la antigua sucursal del Banco de España en Jerez de la Frontera, obra de José de Astiz y Bárcena
}

\author{
José Manuel Moreno Arana \\ Universidad de Sevilla \\ morenoarana@gmail.com
}

La actual sede de la Biblioteca Municipal Central de Jerez de la Frontera, antigua sucursal del Banco de España en la ciudad [1], ha venido considerándose hasta ahora obra del arquitecto Francisco Hernández-Rubio y Gómez (1859-1950) (Merino, 1995: 78-79). No obstante, la consulta de la documentación municipal y de la prensa local de la época obliga a considerar a José de Astiz y Bárcena como el verdadero autor del proyecto. Con este breve trabajo buscamos esclarecer todo su proceso constructivo, dando a conocer los nuevos datos que hemos logrado obtener de las fuentes referidas.

De José Fermín de Astiz y Bárcena no son muchos los datos que hemos localizado. Parece que era madrileño ${ }^{1}$. Nos consta que trabajó bajo la dirección de un arquitecto importante de la época, Enrique María Repullés y Vargas (Navascués, 1973: 288-295), como arquitecto auxiliar en la construcción del edificio de la Bolsa de Madrid, que se inauguró en 1893 (Resumen de Arquitectura, 1893: 51). En 1899 obtiene el cargo de arquitecto del Banco de España (Resumen de Arquitectura, 1900: 16). Como tal, se haría cargo, en solitario o junto a otros arquitectos, de los proyectos para la construcción de diversas sucursales de este organismo en diferentes lugares del país: Lugo (1902), Palencia (1903), Pontevedra (1903), Logroño (1908), Valencia (1918), Badajoz (1918), Oviedo (1923), Haro (1924), Cuenca (1925), Coruña (1926), Pamplona (1927), Alcoy (1928), Sevilla (1928) y Santander (1929) (Banco de España, 1936: s/p)². Junto a ello, entre sus trabajos para clientes particulares, diseñó los mausoleos de las familias Peña y Echarri en el Cementerio de la Sacramental de San Justo de Madrid, realizados en 1901 y 1902 (Saguar, 2002: 122 y 124; Rocha, 2009: 409-410). En su obra se observa cierta versatilidad, transitando su estilo desde el historicismo y el eclecticismo hasta ciertas notas modernistas.

En cuanto al edificio que proyectó para Jerez de la Frontera, podemos seguir la evolución de todo el proceso

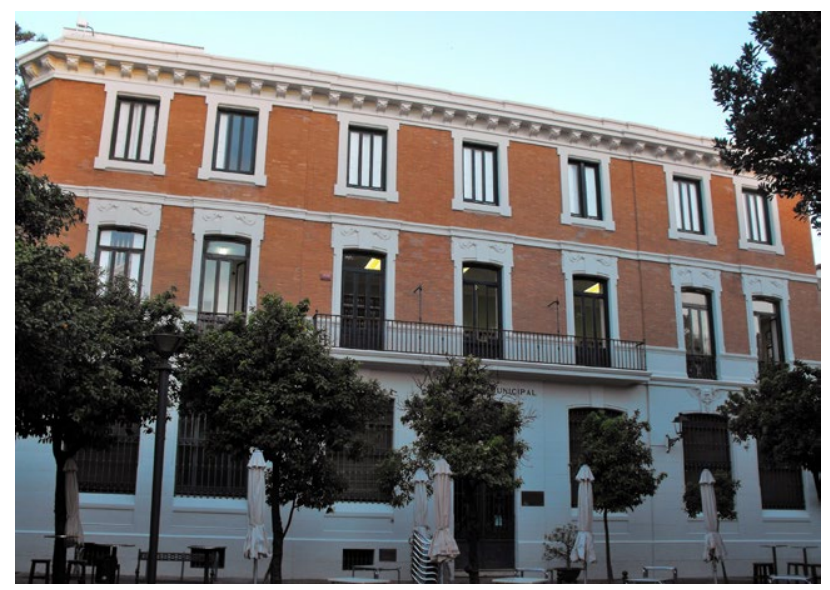

1. Biblioteca Municipal Central de Jerez de la Frontera, antigua sucursal del Banco de España. Vista de su fachada a la plaza General Primo de Rivera

constructivo a través de las páginas del periódico El Guadalete. Así, por ejemplo, tenemos referencias a toda la etapa previa a la edificación, como son la compra del solar y el consecuente derribo de las construcciones existentes. Se trataba de un conjunto de dos casas y dos bodegas, correspondiente a los números 6,7 y 8 de la plaza de Eguílaz (hoy General Primo de Rivera) y 24, 26 y 28 de la calle Alvar López. El 30 de enero de 1902 se anuncia su próxima venta. Es significativo que se apunte que «la plaza de Eguílaz ganará en ornato, pues es indudable que el edificio que levante el Banco para instalar sus oficinas, será de magnífico aspecto». También se informa de que la idea era crear con él una manzana aislada gracias a la apertura de una nueva calle que lo separaría de las casas de la calle San Cristóbal. Se dice asimismo que «muy en breve llegará el Señor arquitecto del Banco, para dirigir las obras que empezarán pronto» (El Guadalete, 1902a). El 17 de marzo siguiente el mismo 


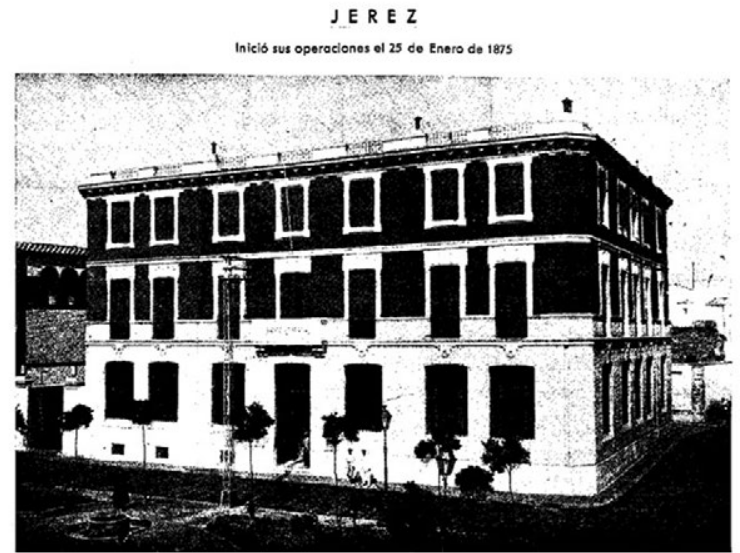

Edificilo inougurodo en el oño 1910. Arquitecto: D. Josb de Astix Bäreence

2. Fotografía del estado original del edificio incluida en el libro: El Banco de España: información gráfica (1936). Se recoge la autoría de José de Astiz y el año de inauguración

rotativo creía que el derribo se llevaría a cabo posiblemente en abril y que las obras durarían año y medio (El Guadalete, 1902b). Ambas predicciones no se cumplirían. De hecho, no es hasta el 10 de mayo cuando el propietario de las casas y bodegas, Manuel Antonio de la Riva y Pomar, firma la escritura de venta al Banco de España ${ }^{3}$. Ya el 20 de junio se anuncia que se sacarían a subasta el día 28 las obras de derribo de dichos inmuebles ante el notario Antonio Navarro y Guerrero (El Guadalete, 1902d). Sin embargo, al no presentarse proposición alguna, quedó desierta dicha subasta 4 . Tras este primer revés, sabemos que el 22 de septiembre el derribo era una realidad, lo que seguía despertando el entusiasmo de la prensa, que aseguraba que una vez «transformada que sea la exigua bodega ó taberna que tanto desdice entre las casas de la plaza de Eguílaz, resultará ésta el paraje más lindo y pintoresco de la localidad» (El Guadalete, 1902e). Aunque hay noticias contradictorias ${ }^{5}$, parece que la demolición siguió activa en el mes siguiente ${ }^{6}$.

El 12 de octubre de ese mismo año se sacan a concurso las obras para la construcción del edificio. Los planos, presupuesto y pliegos de condiciones quedaban expuestos durante veinte días en la Dirección General de Sucursales del Banco de España en Madrid y en la secretaría de la sucursal jerezana (El Guadalete, 1902g). No obstante, la adjudicación y el permiso municipal para el inicio de los trabajos no se producirán hasta 1904, como veremos a continuación. En este sentido, el conocimiento del proyecto comienza pronto a crear ciertos recelos en la opinión pública, que expresa su "extrañeza» tras ver los planos y advertir que no se aprovecharía todo el solar disponible, sino menos de la mitad del mismo. El Guadalete expresa su esperanza de que se reforme este plan pues «nadie se explica que este poderoso establecimiento construya un local tan reducido en ciudad de la importancia de Jerez» (El Guadalete, 1902h).

La primera alusión a José de Astiz que hemos hallado es una visita que hace a Jerez entre el 9 y el 11 de enero de 1903. La prensa local dice que su venida estuvo motivada por «ver la forma de arreglar ciertos puntos relacionados con la edificación del solar» (El Guadalete, 1903a). En este sentido, el día 10 el arquitecto municipal Rafael Esteve y Fernández-Caballero lleva a cabo la demarcación de la línea de fachada de dicho solar (El Guadalete, 1903b).

Tras ello, hay un periodo de más de un año en el que no volvemos a saber nada más. El 26 de marzo de 1904 Astiz firma en Madrid el alzado del edificio que se incluye en la documentación municipal alusiva a la concesión de licencia de obra, que se producirá meses más tarde. De este modo, el 6 de julio se adjudica a la Sociedad «Sr. Bernal y Compañía» la subasta para la construcción y que los trabajos comenzarían en los primeros días de septiembre (La Correspondencia de Cádiz, 1904). Sin embargo, aún quedaba conseguir el visto bueno del Ayuntamiento y para ello el 15 de julio el director de la sucursal envía la correspondiente solicitud. Este documento se encuentra firmado por el arquitecto Francisco Hernández-Rubio, que parece que estaría a cargo de las obras en ausencia de Astiz, aunque los tres alzados que se adjuntan a esta petición no permiten dudar sobre la paternidad del madrileño sobre el proyecto. La documentación incluye también el dictamen favorable del arquitecto municipal, fechado en 18 de julio, así como el de la comisión local de obras públicas y policía urbana, dada el 197. Finalmente, el 20 de julio de 1904 el Ayuntamiento concede la licencia para edificar ${ }^{8}$. Al día siguiente, El Guadalete recoge la noticia, resaltando que la edificación empezaría pronto, aunque volviendo a criticar que resultaría mezquina. La causa que señala es la de la mala alineación efectuada un año antes, que se califica de «defectuosa y disparatada» (El Guadalete, 1904a).

El 5 de agosto de 1904 se dice que había «llegado á ésta el ilustrado arquitecto del Banco de España D. José de Astiz, quien viene para dirigir los comienzos de las obras del 
3. José de Astiz, alzado del proyecto de Sucursal del Banco de España en Jerez de la Frontera. Fachada a la plaza de Eguílaz, 1904

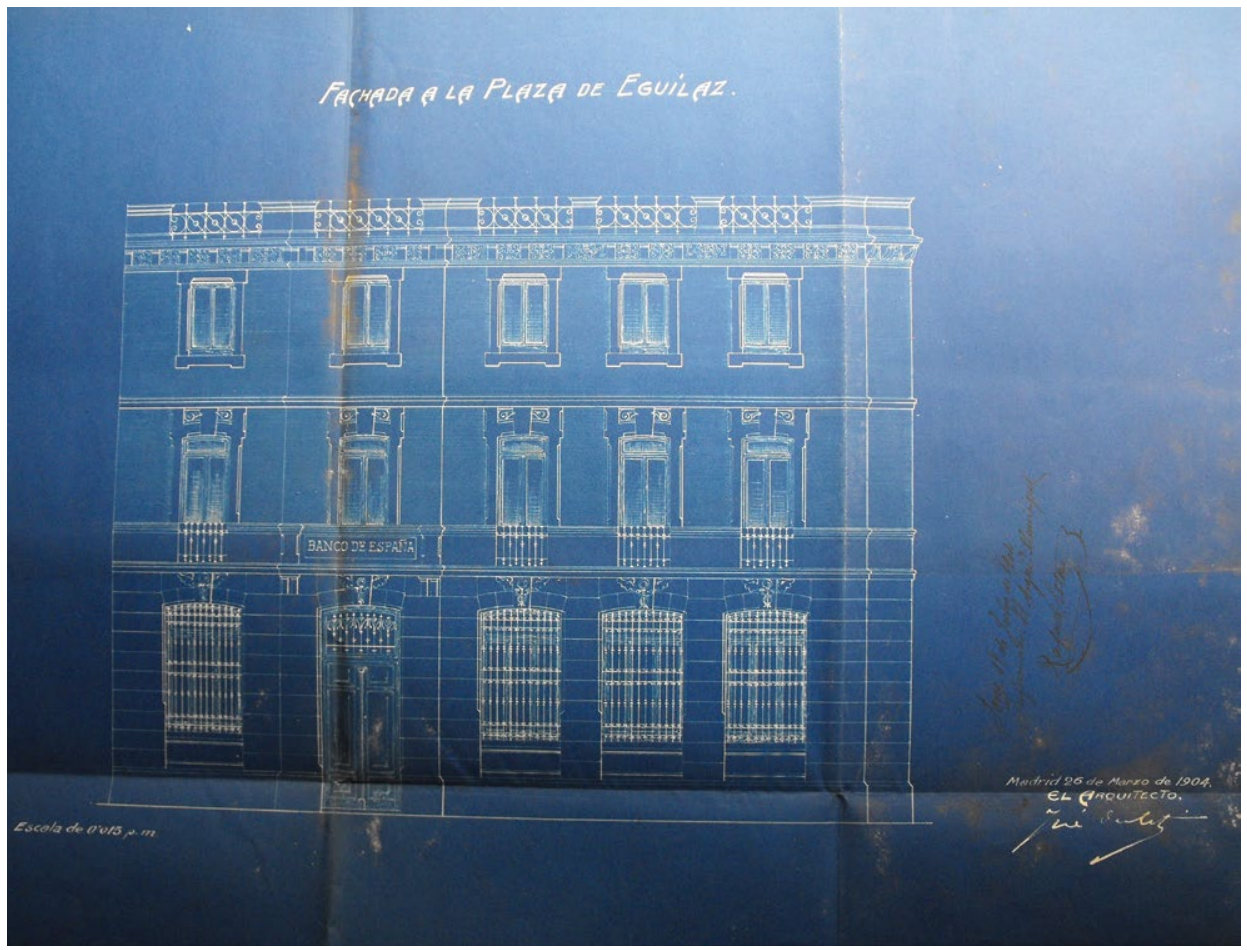

nuevo edificio que va á construirse para la Sucursal» (El Guadalete, 1904b). El 10 de agosto se presenta una instancia del director de la sucursal solicitando el traslado de las tuberías de agua que atraviesan el solar y que impedían la realización de las obras ${ }^{9}$. Al día siguiente, El Guadalete hace alusión a la sesión municipal en la que fue leído el escrito y alude a una intervención del concejal Julio González Hontoria, que «pide que se obligue a que se labre la parte del solar que queda al descubierto, bien con un jardín ó con otra cualquier cosa que hermosee aquel lugar» (El Guadalete, 1904c) ${ }^{10}$.

Salvando estos inconvenientes, las obras serían una realidad en los meses siguientes. A través del mismo diario tenemos noticia de diferentes visitas que a la ciudad hace Astiz para inspeccionar los trabajos. Se suceden, de este modo, el 18 de octubre de 1904 (El Guadalete, 1904d), el 16 de abril (El Guadalete, 1905a) y 19 de julio de 1905 (El Guadalete, 1905b) y el 7 de febrero de 1906 (El Guadalete, 1906).

Finalmente, el 17 de enero de 1907 llegan a Jerez desde Madrid el consejero del Banco de España José Santos y Fernández Laza y el arquitecto José de Astiz, «haciéndose cargo del nuevo edificio levantado en la Plaza de Eguílaz»
(El Guadalete, 1907). En cualquier caso, diferentes fuentes apuntan a que la inauguración no tuvo lugar hasta 1910. De este modo, una vieja publicación del propio Banco de España hace alusión a esa fecha. Es importante destacar además que se recoge en ella también la autoría de José de Astiz, lo que viene a incidir en los datos que hemos ido aportando en este estudio (Banco de España, 1936: s/p) [2] ${ }^{11}$.

Lo anterior nos hace pensar que quizás la conclusión no se produjo en 1907. De hecho, la comparación de los alzados dibujados en 1904 con las fachadas actuales demuestran que las quejas por el escaso tamaño del edificio fueron oídas y el proyecto original fue ampliado, lo que debió de prolongar las obras. Así, los alzados correspondientes a la plaza de Eguílaz [3] y a la calle Alvar López [4] nos muestran sendas fachadas de tres cuerpos con cinco vanos por cada uno de ellos, frente a los siete que hoy existen. Asimismo, la puerta de acceso por la plaza de Eguílaz no aparece en medio, como terminó disponiéndose, sino descentrada. Pero salvando esta ampliación, que dio mayor extensión al inmueble y una perfecta simetría a dichas fachadas, el proyecto firmado por Astiz en 1904 fue seguido con gran fidelidad. Esto 


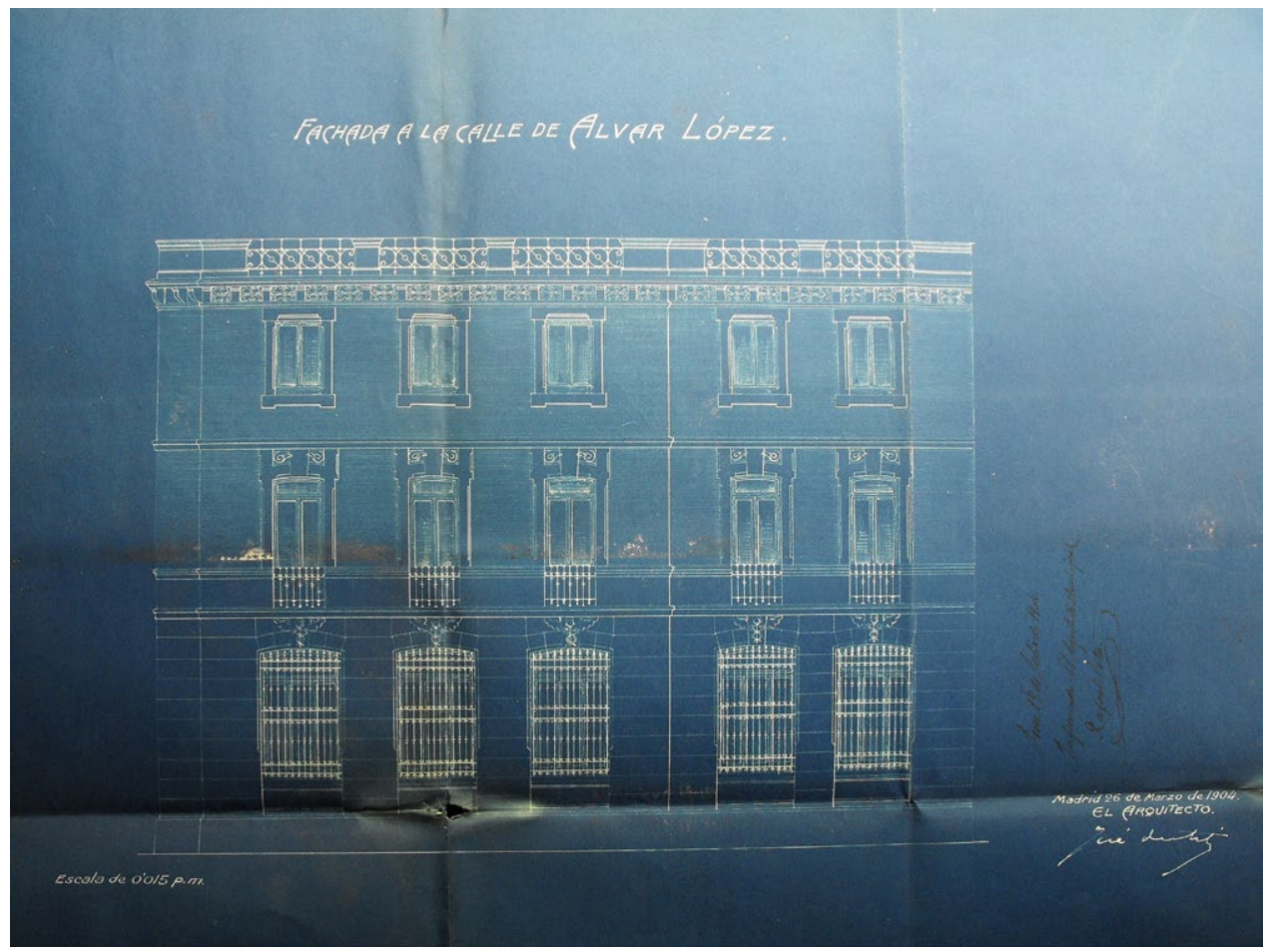

4. José de Astiz, alzado del proyecto de Sucursal del Banco de España en Jerez de la Frontera. Fachada a la calle Alvar López, 1904 lo vemos, por ejemplo, en la combinación de piedra artificial y ladrillo visto, las esquinas achaflanadas o el preciso diseño de los enmarques de las ventanas, que en la planta baja incluyen el motivo en relieve del caduceo, símbolo de Mercurio, el dios del Comercio. Un detalle, este último, que fue también reiteradamente empleado en la decoración de otro edificio donde consta la intervención de Astiz, la Bolsa de Madrid. Sí existen algunas diferencias entre el proyecto y la realización definitiva en la cornisa y el antepecho que sirven de remate a todas las fachadas ${ }^{12} \mathrm{y}$, sobre todo, en el diseño de rejas y puertas, pormenores donde sí estaría la mano de Francisco Hernández-Rubio, cuya firma figura en la puerta principal de hierro que se abre a la plaza, cuyas líneas modernistas contrastan con la sobriedad del resto del conjunto ${ }^{13}$.

\section{Notas}

1 En 1907 vivía en la calle del Arenal n. ${ }^{\circ} 27$ de Madrid cuando envía una instancia a su ayuntamiento relativa a la normativa municipal sobre sifones en las bajadas de desagüe de las casas (La Construcción Moderna, 1907: 215-216). En 1915 era presidente de una congregación o hermandad de arquitectos con sede en la iglesia de San Sebastián de Madrid (La Correspondencia de España, 1915: 6).

2 Los años entre paréntesis aluden a la fecha de inauguración de cada edificio. Agradecemos al personal del Archivo del Banco de España que nos informara de la existencia de esta publicación.

3 Archivo de Protocolos Notariales de Jerez de la Frontera (A.P.N.J.F.), tomo 4542, notario Antonio Navarro, año 1902, ff. 923-937. La referencia a la firma de la escritura aparece recogida en la prensa (El Guadalete, 1902c).

4 A.P.N.J.F., tomo 4542, notario Antonio Navarro, año 1902, ff. 1363-1364.

5 Al parecer, en 1905 se descubre una escultura de sirena, hoy en el Museo Arqueológico Municipal de Jerez, «al derribarse unas casas en la plaza de Eguílaz para construir el edificio que sirve de Sucursal del Banco de España» (Pescador, 1916: 13-14).

6 Hay constancia de ello por un accidente de trabajo acaecido allí el 3 de octubre (El Guadalete, 1902f).

7 Archivo Histórico Municipal de Jerez de la Frontera (A.H.M.J.F.), Protocolo Municipal, Policía Urbana, tomo 389 
8 A.H.M.J.F., Actas Capitulares, 1904, pp. 239-240.

9 A.H.M.J.F., Actas Capitulares, 1904, pp. 269-270.

10 Es interesante señalar que Julio González Hontoria, que había sido años antes alcalde de Jerez, construyó en 1894 su casa en uno de los lados de la misma plaza de Eguílaz y la dirección de las obras corrió a cargo de Francisco Hernández-Rubio, precisamente (Merino, 1995: 46).

111910 es la fecha que recoge también Merino Calvo (Merino, 1995: 78).

12 Este antepecho estaba dotado de rejas en el proyecto y así estuvo hasta una reforma de mediados del siglo XX en la que fue macizado. También se transformó y agrandó el balcón central de la fachada principal. El interior asimismo se halla muy alterado debido a las adaptaciones que ha sufrido a causa de su nueva función de biblioteca, que tiene desde 1986.

13 En unas pequeñas cartelas hay dos inscripciones: "ARQUITECTO FCO. HZ.-RUBIO»y «I. GUTIERREZ Y CÍA. JEREZ». La segunda remite a la fundición que ejecutó el trabajo (Caballero, 2010). El diseño de la puerta es muy próximo al que encontramos en otras puertas de obras de Hernández-Rubio de esos años (Merino, 1995: 75 y 76)

\section{Bibliografía}

BANCO DE ESPAÑA (1936), El Banco de España: información gráfica, Asociación General de Empleados del Banco de España, Madrid, s/p. CABALLERO RAGEL, Jesús (2010), «La empresa de Fundición "Gutiérrez y Cía”», Diario de Jerez, 2 de febrero.

El Guadalete (1902a), 30 de enero.

- (1902b), 17 de marzo.

- (1902c), 12 de mayo.

- (1902d), 20 de junio.

- (1902e), 22 de septiembre

- (1902f), 3 de octubre.

- (1902g), 12 de octubre.

- (1902h), 17 de octubre.

- (1903a), 10 y 12 de enero.

- (1903b), 11 de enero.

- (1904a), 21 de julio.

- (1904b), 5 de agosto.

- (1904c), 11 de agosto.

- (1904d), 19 y 20 de octubre.

- (1905a), 18 de abril.

- (1905b), 20 de julio.

- (1906), 8 de febrero.

- (1907), 17 de enero de 1907.

La Construcción Moderna (1907), 15 de julio, pp. 215-216.

La Correspondencia de Cádiz (1904), 6 de julio.

La Correspondencia de España (1915), 19 de enero, p. 6.

MERINO CALVO, José Antonio (1995): El arquitecto jerezano Francisco Hernández-Rubio y Gómez. 1859-1950, Ayuntamiento de Jerez de la Frontera, Jerez de la Frontera.

NAVASCUÉS PALACIO, Pedro (1973), Arquitectura y arquitectos madrileños del siglo XIX, Instituto de Estudios Madrileños, Madrid.

PESCADOR Y GUTIÉRREZ DEL VALLE, Mariano (1916), Apuntes para un catálogo de los objetos que existen en el depósito arqueológico anexo a la biblioteca municipal de Jerez de la Frontera, Imprenta de Manuel Álvarez Rodríguez, Cádiz.

Resumen de Arquitectura (1893), 1 de julio, p. 51.

- (1900), 1 de febrero, p. 16. 
ROCHA ARANDA, Oscar da (2009), El modernismo en la arquitectura madrileña: génesis y desarrollo de una opción ecléctica, Consejo Superior de Investigaciones Científicas, Madrid.

SAGUAR QUER, Carlos (2002), «El Cementerio de la Sacramental de San Justo: historia y arquitectura», Anales del Instituto de Estudios Madrileños, tomo XLII, pp. 122 y 124. 